\title{
Mechanism and Control of Hydrogen Induced Abnormal Sticky Behavior in Slab Casting Mould
}

\author{
Preeti Prakash SAHOO, ${ }^{1 / *}$ Bapin Kumar ROUT ${ }^{1)}$ and Pabitra PALAI ${ }^{2)}$ \\ 1) Research and Development, Tata Steel Limited, Jamshedpur-831001 India. \\ 2) Flat Product Technology Group, Tata Steel Limited, Jamshedpur-831001 India.
}

(Received on November 28, 2014; accepted on February 13, 2015)

\begin{abstract}
Abnormal sticky behavior in continuous casting of steel refers to an event when in an instrumented mould, temperatures of all layers of thermocouple drop to a near single temperature level and thus doesn't help in identifying any phenomena happening in the mould. No signal is generated to capture any sticker or any other abnormal event occurring in the mould. In this situation the risk of sticker breakouts increases significantly. The knocks on effect are casting delays and slab downgrades. This study was carried out by collecting top slag samples and mould slag films from the mould for both normal and abnormal heats. Optical microscopy and SEM images revealed presence of pores in the slag film complemented with large crystals in abnormal heats. Porous structure in the slag film creates high thermal resistance to the heat flow from the slab to the mould, which retards the solidification of the slab. Also crystalline structure of slag film hinder heat transfer between solidifying shell and water cooled mould and lead to abnormal sticky behavior. Measurement of diffusible hydrogen content of liquid steel in tundish was measured to find out if hydrogen is accelerating the slag crystallization. It was found out that, in case of abnormal heats hydrogen content was 30-40\% higher than the normal heats. The primary and secondary steelmaking parameters were looked into and it was found out that the choice of material added and addition pattern along with treatment time has major contribution in increasing hydrogen content of steel.
\end{abstract}

KEY WORDS: abnormal sticky; slag film; crystallization; hydrogen in steel; differential scanning calorimetry.

\section{Introduction}

It is well known that two of the major functions of the mould flux in continuous casting of steel are, (i) to control horizontal heat transfer between the water cooled mould and the solidifying steel shell and (ii) to provide sufficient lubrication between the solidified steel shell and the oscillating mould. The lubrication is provided by the liquid slag film formed due to the non-wettability of flux with the metals and it is supported by adequate powder melting. Horizontal heat transfer is controlled by the solid slag film layer which is formed due to water cooling of the mould (Shown schematically in Fig. 1). Control of horizontal heat transfer is important, as adequate shell thickness of the solidifying steel is the paramount requirement for smooth progress of continuous casting. Otherwise the shell may puncture due to liquid ferrostatic pressure and may lead to a sticker breakout. The slag film formed between the mould and strand consists of three distinguishable layers: completely glassy layer close to mould side, crystalline layer in the middle and liquid film in contact with the steel. ${ }^{1)}$ It is reported that the amount of crystalline phase in the slag film controls the heat transfer rate in the mould. ${ }^{2)}$ This is due to the radiation heat flux, which controls the heat transfer rate, and the rate

\footnotetext{
* Corresponding author: E-mail: p.sahoo@tatasteel.com DOI: http://dx.doi.org/10.2355/isijinternational.55.993
}

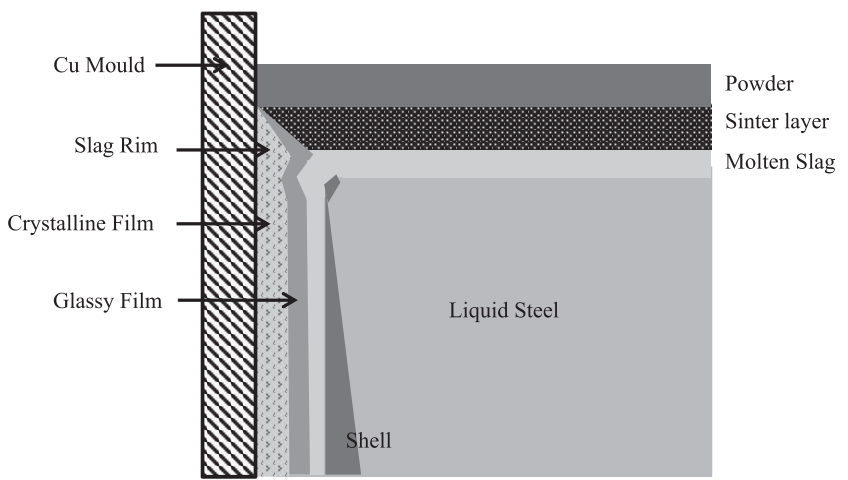

Fig. 1. Schematic diagram of continuous casting mould showing slag film.

decreases in the presence of crystalline phases. ${ }^{3)}$ Slags with high crystallization tendency operates with reduced casting speed as these slags increases the possibility of sticker type breakouts due to high friction generated between solidifying shell and the mould. ${ }^{4)}$ Thus the solidification temperature and heat transfer ability of a mould slag are the two essential properties responsible for prevention of sticker type breakouts as well as the final quality of slabs. ${ }^{5)}$ Sticker breakout, the most catastrophic phenomena, not only delays the casting operation but also affects the process economics adversely. In order to prevent sticker breakout, breakout detection systems (BDS) have been developed and 
are being used practically ${ }^{6,7)}$ in many steel industries. This system uses multiple layers of thermocouples attached to the copper mould to measure the specific heat transfer rate in the mould. Any abnormality during casting is captured by the system and takes counter measures to prevent/reduce the occurrence of any abnormal situation. Some literature suggests that hydrogen from liquid steel affects the slag film behavior. The generation of hydrogen gas from the surface of solidified shell of carbon steel was confirmed by the experiments at initial stage of solidification. The amount of hydrogen gas increases with increasing hydrogen content in molten steel. When the hydrogen gas generated from shell surface blocks flow of mold flux into the gap, the possibil-

(a)

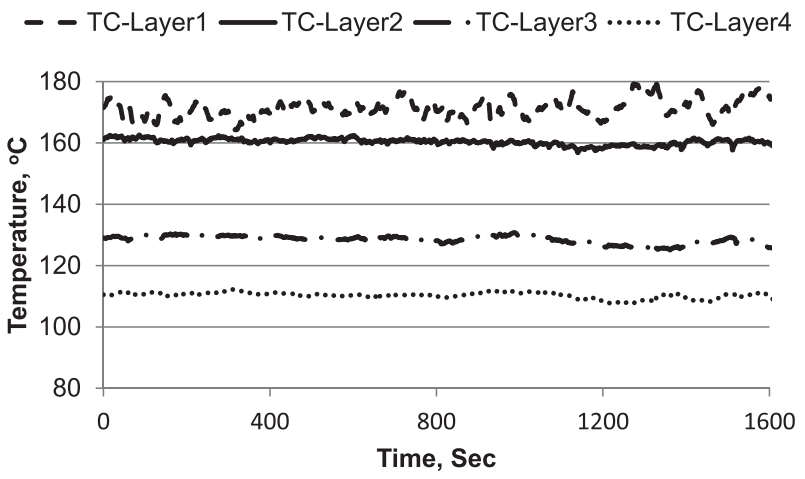

(b)

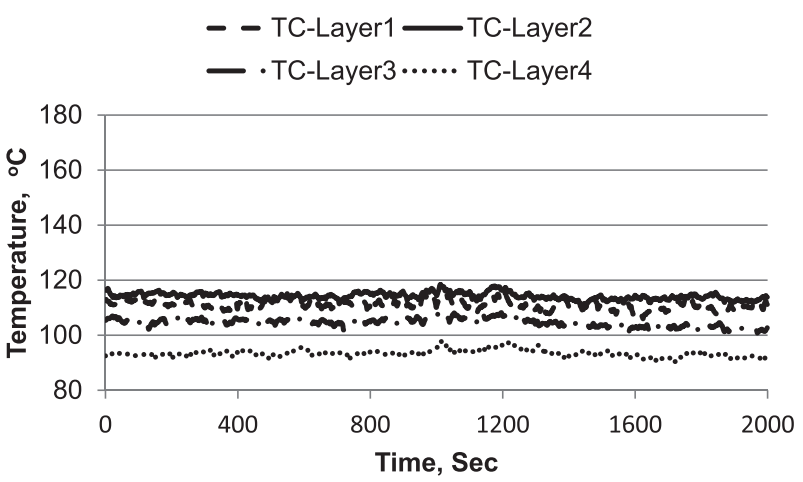

Fig. 2. (a) Thermocouple reading of all 4 thermocouple layers (normal heat). (b) Thermocouple reading of all 4 thermocouple layers (abnormal heat).

\section{$\varangle$ Normal Heat $\rightarrow$ Abnormal Heat}

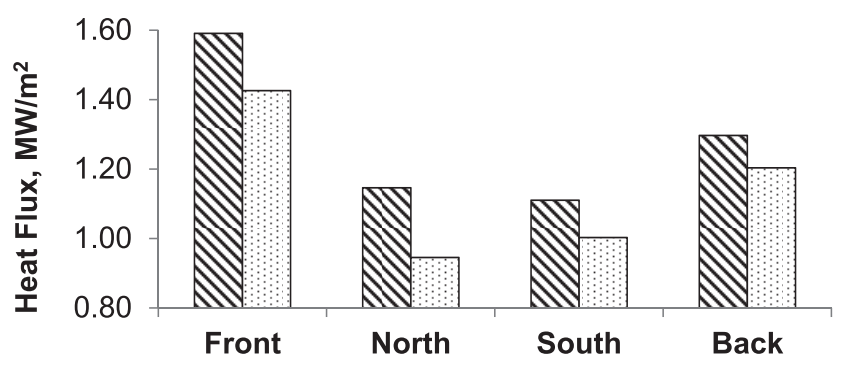

Fig. 3. Mould heat flux difference for abnormal and normal heats. ity of sticker breakout in continuous casting increases. ${ }^{8)}$ In some other literature it is reported that during casting of Silicon (Si) killed steel water vapor in the atmospheric air get absorbed into molten flux pool as hydroxyl ions. As Si is a weak deoxidizing element hydroxyl ions are not reduced and form micropores in the slag films during crystallization. The micropores, reduces heat transfer at the mould meniscus and sometimes results in a sticker breakout. ${ }^{9)}$ It is also reported that lower hydrogen contents, lower casting speeds and higher consumption rates of mold powder are preferable to prevent the hydrogen-induced breakouts of aluminumkilled non-degassed steel. ${ }^{10)}$

Thermocouple temperature inversion is an abnormal phenomenon that occurs during casting of steel wherein the temperature readings of the upper layer thermocouple in the mould drop and match with those of the second layer thermocouple. Figure 2(a) shows the normal casting operations where all layers of the thermocouple are reasonably parallel to each other and the upper thermocouple reading which is closer to meniscus is around $180^{\circ} \mathrm{C}$. However in Fig. 2(b) the reading of first layer thermocouple has dipped and overlapping with the second layer of thermocouple, which indicates the abnormality in casting. When the temperature of upper thermocouple drops below the lower thermocouple, an alarm is triggered. This alarm automatically slows down the casting speed to $0.8 \mathrm{~m} / \mathrm{min}$ to reduce the risk of a sticker breakout resulting in lower productivity of the caster. Heat flux data for 4 faces of the mould shows there is a significant difference between abnormal and normal heats, which is shown in Fig. 3. This figure shows that in case of abnormal heats, the heat flux extracted by the cooling water is significantly lower than the normal heat due to poor heat transfer in the mould. This is referred as abnormal sticky behavior in mould. The knock on effects are casting delays, slab downgrades and sometime it leads to breakouts.

Many researchers through laboratory experiments reported that crystallization of slag happens faster due to increase in hydrogen content in steel. ${ }^{11-13)}$ Kajitani et al. ${ }^{14)}$ established a mechanism of formation of micro pores in slag film due to increase in hydrogen content in molten steel during the casting of Si killed steels.

The objective of the present work is to identify the mechanism behind abnormal sticky behavior in slab casting mould and hence take necessary control to avoid this phenomenon.

\section{Experimentation}

The present study, include top slag collection, slag film collection and hydrogen measurement of liquid steel. These experiments were performed during same period for both normal and abnormal heats using the same mould powder. The composition of the mould powder used during the investigation period is reported in Table 1. Also effort was made to characterise slag film and top slag samples to figure

Table 1. Composition of mould powder used during the experimentations.

\begin{tabular}{lccccccccccc}
\hline Composition (\%) & $\mathrm{CaO}$ & $\mathrm{SiO}_{2}$ & $\mathrm{MgO}$ & $\mathrm{MnO}$ & $\mathrm{Al}_{2} \mathrm{O}_{3}$ & $\mathrm{TiO}_{2}$ & $\mathrm{~K}_{2} \mathrm{O}$ & $\mathrm{Fe}_{2} \mathrm{O}_{3}$ & $\mathrm{Na}_{2} \mathrm{O}$ & $\mathrm{C}$ & $\mathrm{F}$ \\
\hline Powder for LC & 37.2 & 39.1 & 0.6 & 0.15 & 4.5 & 0.2 & 1.0 & 1.6 & 10.1 & 5.8 & 8.5 \\
\hline
\end{tabular}


out the influence of abnormal sticky behavior on casting process. Therefore slag film/top slag samples were collected and investigated for both normal and abnormal situations. Optical microscopic studies of the samples were performed to identify microstructural differences between the normal and abnormal heats. In addition, the slag films of abnormal heats were characterised for analysing the degree of crystallinity and porosity using Scanning Electron Microscopy (SEM) and Electron Dispersive X-ray Spectroscopy (EDS) analysis. Also hydrogen content of liquid steel in tundish was measured to record the hydrogen content for both normal and abnormal heats.

\subsection{Collection of Slag Film}

Slag film from the mould was collected by lowering the steel level in the mould during the end of a casting sequence. Low carbon grades were considered for analysis as the frequency of such abnormal phenomena was higher in these grades considering the volume of LC grades cast. The collected slag films of both normal and abnormal conditions are shown in Fig. 4.

\subsection{Top Slag Collection}

Mould top slag samples were taken out from the mould by using a stainless steel spoon under both normal and abnormal casting conditions where there was abnormal sticky behavior. After placing the liquid slag sample on a stainless steel plate it was allowed to air cool. Once the slag sample reaches room temperature, it was collected and sent for chemical analysis and other analyses. The following compounds were analysed from the slag samples- $\mathrm{Fe}_{2} \mathrm{O}_{3}$, $\mathrm{MnO}, \mathrm{SiO}_{2}, \mathrm{Al}_{2} \mathrm{O}_{3}, \mathrm{CaO}, \mathrm{MgO}, \mathrm{Na}_{2} \mathrm{O}, \mathrm{TiO}_{2}, \mathrm{~K}_{2} \mathrm{O}$, and $\mathrm{CaF}_{2}$. Further optical microscopy and SEM was performed to investigate morphology and phases present in both normal and abnormal slag samples.
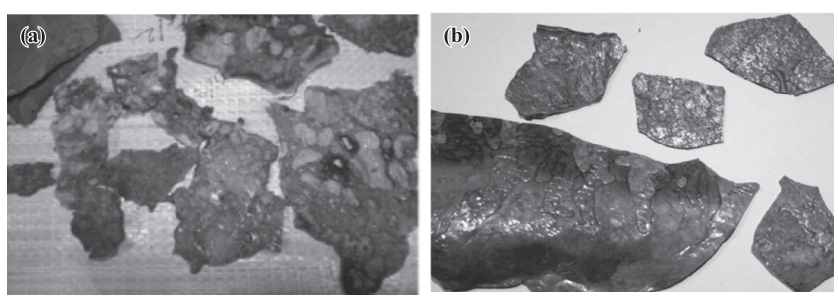

Fig. 4. Mould slag film from normal and abnormal heats (a) abnormal slag film (b) normal slag film.

\subsection{Measurement of Hydrogen in Liquid Steel}

LECO Evacuated Metal Sampler was used to collect samples for diffusible hydrogen measurement. The sampler was dipped in the molten steel and immediately quenched in chilled water. Further these dual-wall samplers were sent for hydrogen analysis by using LECO TCH600. This instrument uses inert gas fusion (IGF) followed by thermal detector (TC) to measure the diffusible hydrogen content in the sample. The value of diffusible Hydrogen measured by this technique is a relative value as it is measured after the steel is in solid state.

\section{Results and Discussions}

\subsection{Chemical Composition of Slag Film and Mould Slag}

Chemical analysis of collected slag samples was carried out for both normal and abnormal casting conditions. The chemical analysis report is summarized in Table 2 and it can be observed that the chemical compositions of both the cases are nearly the same. Similarly Table 3 shows the chemical compositions of slag films collected in both normal as well as abnormal heats. The chemical composition of mould slag in both normal and abnormal sticky behavior heats were similar, suggesting no compositional effect on abnormal behavior.

\subsection{Effect of Alumina}

Alumina in the mould slag plays an important role to control the viscosity and heat transfer properties. If the alumina in mould slag is higher the viscosity will increase and the slag infiltration will decrease. This will induce crystallization of slag film as fresh liquid slag flow into the mould reduces. Therefore mould top slag analysis of several heats from normal as well as abnormal abnormal sticky behavior heats were investigated. The chemical analysis of slag alumina percentage is shown in Fig. 5. It is confirmed that in the top slag, the variation in alumina percentage for both normal and abnormal casting condition were minimal.

\subsection{Analysis of Slag Films}

The collected mould flux films from the meniscus region were cut in transverse direction of casting. A cross section of the films was cold mounted with resin. The mounted samples were polished and observed under optical microscope as well as under SEM.

Table 2. Chemical Analysis of mould top slag (both normal and abnormal heats).

\begin{tabular}{lccccccccccc}
\hline \multicolumn{1}{c}{ Composition (\%) } & $\mathrm{CaO}$ & $\mathrm{SiO}_{2}$ & $\mathrm{MgO}$ & $\mathrm{MnO}$ & $\mathrm{Al}_{2} \mathrm{O}_{3}$ & $\mathrm{TiO}_{2}$ & $\mathrm{~K}_{2} \mathrm{O}$ & $\mathrm{Fe}_{2} \mathrm{O}_{3}$ & $\mathrm{Na}_{2} \mathrm{O}$ & $\mathrm{C}$ & $\mathrm{F}$ \\
\hline Top slag (Normal heat) & 33.69 & 37.26 & 0.57 & 1.14 & 10.44 & 0.26 & 0.88 & 1.7 & 10 & 0.08 & 9.35 \\
Top slag (Abnormal heat) & 34.26 & 38.06 & 1.46 & 1.64 & 8.98 & 0.21 & 0.85 & 2.55 & 10.03 & 0.1 & 9.55 \\
\hline
\end{tabular}

Table 3. Chemical Analysis of mould slag films (both normal and abnormal heats).

\begin{tabular}{lccccccccccc}
\hline \multicolumn{1}{c}{ Composition (\%) } & $\mathrm{CaO}$ & $\mathrm{SiO}_{2}$ & $\mathrm{MgO}$ & $\mathrm{MnO}$ & $\mathrm{Al}_{2} \mathrm{O}_{3}$ & $\mathrm{TiO}_{2}$ & $\mathrm{~K}_{2} \mathrm{O}$ & $\mathrm{Fe}_{2} \mathrm{O}_{3}$ & $\mathrm{Na}_{2} \mathrm{O}$ & $\mathrm{C}$ & $\mathrm{F}$ \\
\hline Slag Film (Normal heat) & 32.9 & 33.83 & 0.39 & 2.79 & 9.5 & 0.37 & 0.92 & 1.52 & 8.92 & 0.09 & 9.12 \\
Slag Film (Abnormal heat) & 34.5 & 35.94 & 0.52 & 3.09 & 8.59 & 0.26 & 1.17 & 0.94 & 9.34 & 0.09 & 9.41 \\
\hline
\end{tabular}




\subsubsection{Optical Microscopy of Slag Films}

Figures 6(a) and 6(b) show the optical micrograph of the mould flux film for normal as well as abnormal heats. The three distinguishable layers that is, thin glassy layer with small crystals at the mould side, crystalline layer in the middle and a thick glassy layer towards strand side were observed in case of the normal slag film as shown Fig. 5(a). However the slag film of abnormal heat shows presence of large sized crystals and pores towards mould side. A glassy

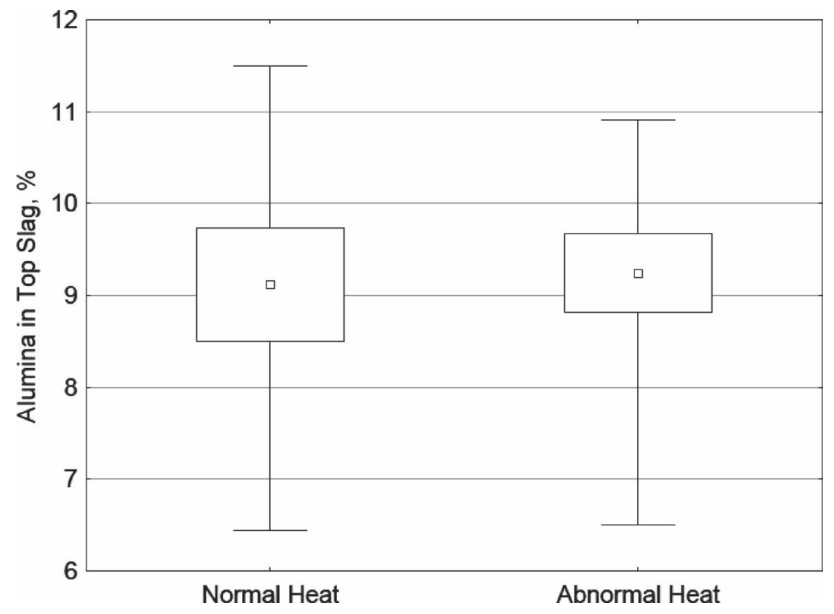

Fig. 5. Alumina content of top slag for both normal and abnormal heats. layer with fine grained crystallites was observed towards the strand side as can be seen from Fig. 5(b). This suggests that due to presence of large sized pores and large number of crystals, heat transfer through the slag film was poor in case of abnormal heats which reduces the thermocouple temperature reading embedded in the mould. As the slag film has very low thermal conductivity from the meniscus itself, the top two layers thermocouple reading matches or cross each other showing abnormal sticky behavior phenomena.

\subsubsection{SEM-EDS Analysis of Mould Slag Film}

SEM characterization of slag film collected in both abnormal casting condition e.g. during abnormal sticky behavior and normal conditions confirms three distinguishable layers. In normal slag film (Fig. 7(a)), the side in contact with the strand composed of a complete glassy layer and towards mold side a glassy layer with fine dispersed crystals was observed. Also a fully dendritic structure was observed in the middle layer of a normal slag film. This may be due to the initiation of crystal formation in the amorphous layer present in contact with the strand. Figure 7(b) shows the SEM characterization of mould slag film collected during abnormal sticky behavior heats. It can be observed that the slag film contains crystals throughout the film. The side adjacent to the mould side composed of very large size crystals as compared to the normal slag film and gradually the crystal size decreases towards strand side. EDS analysis of
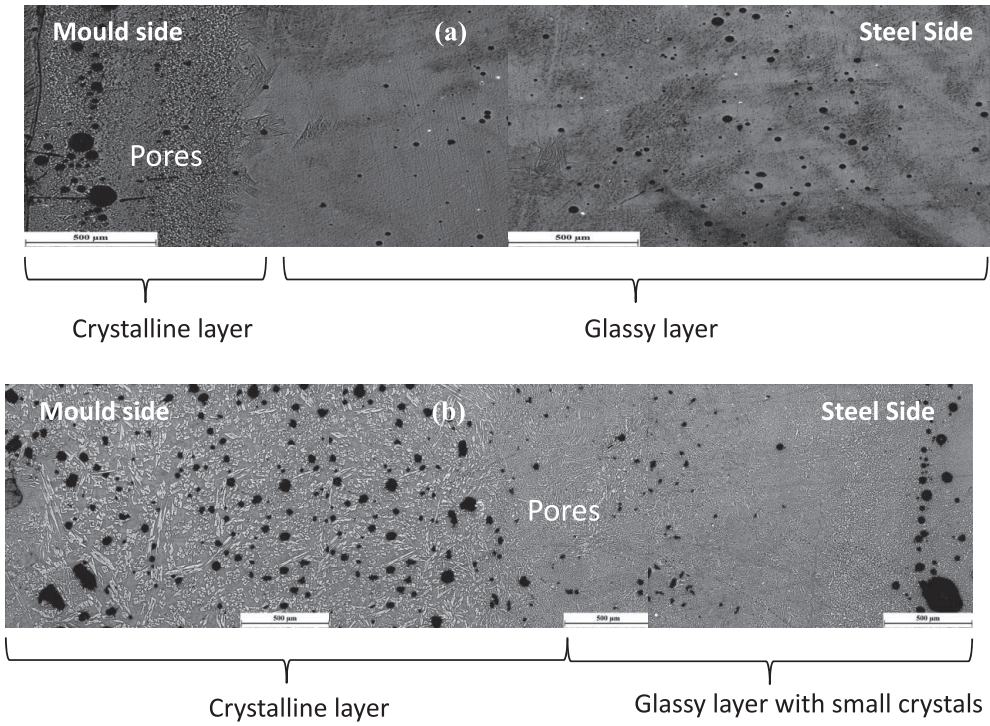

Fig. 6. Optical micrograph of (a) normal slag film (b) abnormal slag film.
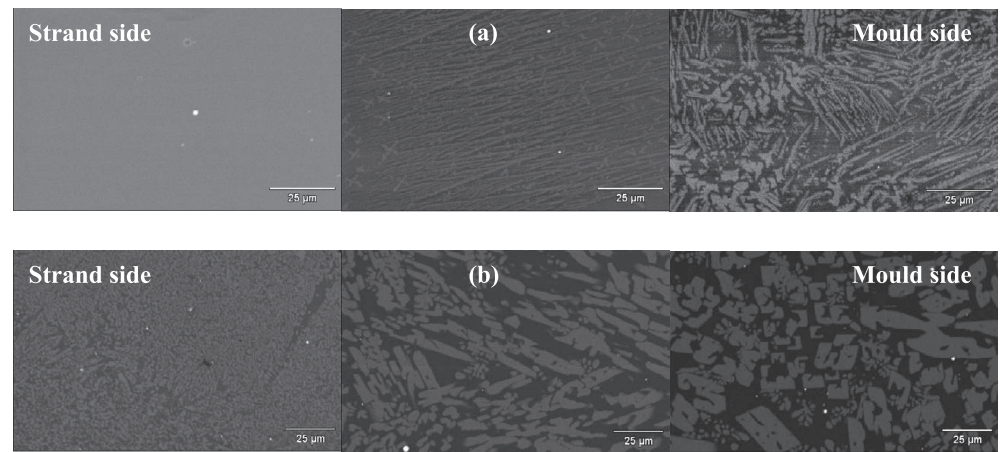

Fig. 7. SEM characterization of slag films for (a) normal and (b) abnormal heats. 

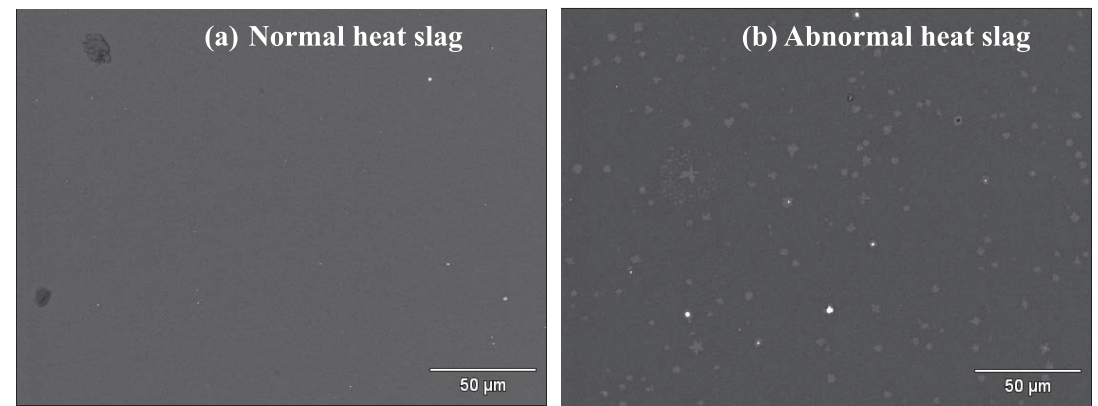

Fig. 8. SEM analysis of top slag for both (a) normal and (b) abnormal heats.

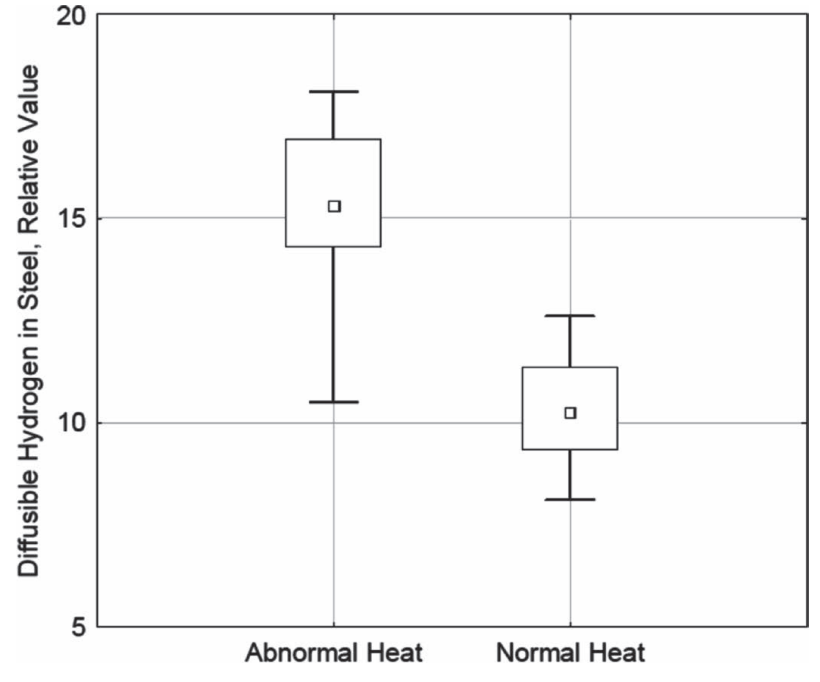

Fig. 9. Hydrogen content in liquid steel for both normal and abnormal heats.

the crystallised area of abnormal slag film showed formation of large cuspidine $\left(\mathrm{CaO} \cdot \mathrm{SiO}_{2} \cdot \mathrm{CaF}_{2}\right)$ crystals.

\subsection{Mould Slag Analysis}

Figures 8(a) and 8(b) show the SEM analysis of top mould slag in normal and abnormal heats.

It is observed that in the case of a normal heat the slag is completely glassy whereas for an abnormal heat the slag consists of crystals (dull spots in Fig. 8(b); bright spots are steel) uniformly distributed throughout the sample. Further the size of crystals present in the slag was measured to be 4-5 $\mu \mathrm{m}$ and the volume fractions of the crystalline phases are found to be about $6 \%$. This suggests that once the liquid slag will penetrate between the mould and strand gap, there is higher chance of crystallite formation in case of abnormal heats.

\subsection{Hydrogen Content in Liquid Steel}

In order to study the effect of hydrogen on abnormal sticky behavior hydrogen measurement was carried out in tundish and compared with the hydrogen ppm in normal heats. Figure 9 shows the average value of diffusible hydrogen content in steel in both normal as well as abnormal conditions. The average hydrogen content of liquid steel in normal heat was $\sim 10.5$, whereas the value is $\sim 15.5$ in case of abnormal sticky heats.

The effect is evident from Fig. 2(b) where an unsteady behavior of the top thermocouple (layer 1) was observed.
This indicates meniscus instability during casting. Also an effect on mould powders melting characteristics was observed and this led to poor heat transfer, shallow slag pool depth (Fig. 9), porous slag film and large crystalline structures (Fig. 7(b)) etc. Due to the meniscus instability the temperature reading of the upper thermocouple crosses the second layer thermocouple and the BDS alarm was triggered several times. Thus, the theoretical links with hydrogen, an element that is known to give operational problems with respect to stickers and increased risk of breakout, have been investigated. The plant trials clearly show that there is a relationship exists between higher hydrogen content in steel and irregular heat transfer.

\subsection{Factors Affecting Higher Hydrogen in Steel}

The next step of the study was to identify and control the source of hydrogen in steel. For this the up-stream parameters were analysed to make out a possible mechanism to control the hydrogen in steel. The possible sources of hydrogen are:

1) Moisture from tundish refractory due to inefficient tundish preheating

2) Hydrated lime addition

3) Coke addition

Effects of following sources were studied and it was found that for both normal abnormal cases similar amount of material was added from same batch. So other factors such as ferro alloy addition and additions in primary steelmaking were considered. As degassing by Ar purging in LF is an important factor to remove certain amount of gases, it was also considered alond with addition of ferro alloy. So both addition and purging duration in LF was looked at to find out the possible reason for higher hydrogen.

\subsubsection{Role of High Carbon Ferro Manganese Addition in LF}

Increase in one percent of $\mathrm{Mn}$ in steel increases the hydrogen solubility by $3-4 \mathrm{ppm}$. So when a grade with high manganese content is made it should be properly degassed before casting. As the density of High Carbon Ferro Manganese ( $\mathrm{HC} \mathrm{Fe}-\mathrm{Mn}$ ) which is a major source for $\mathrm{Mn}$ in steel is greater than liquid steel, there is a chance settling down of $\mathrm{HC} \mathrm{Fe-Mn} \mathrm{in} \mathrm{the} \mathrm{bottom} \mathrm{of} \mathrm{the} \mathrm{ladle.} \mathrm{If} \mathrm{proper}$ purging duration is not given after addition of $\mathrm{HC} \mathrm{Fe}-\mathrm{Mn}$ chances of hydrogen solubility increases.

Purging duration in LF is dependent on the amount of addition made. So a better representation would be to consider the amount of addition made and the purging duration 


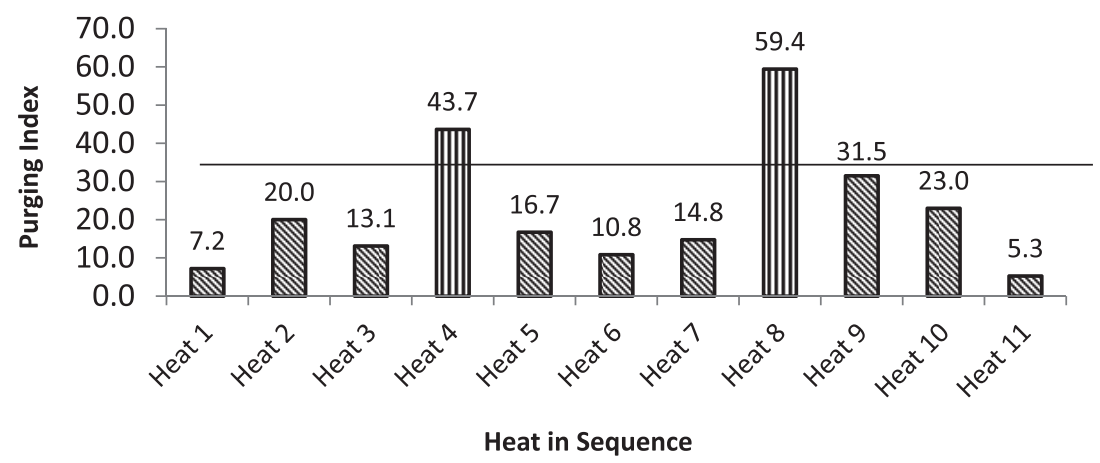

Fig. 10. Combined effect of amount of addition made and the purging duration.

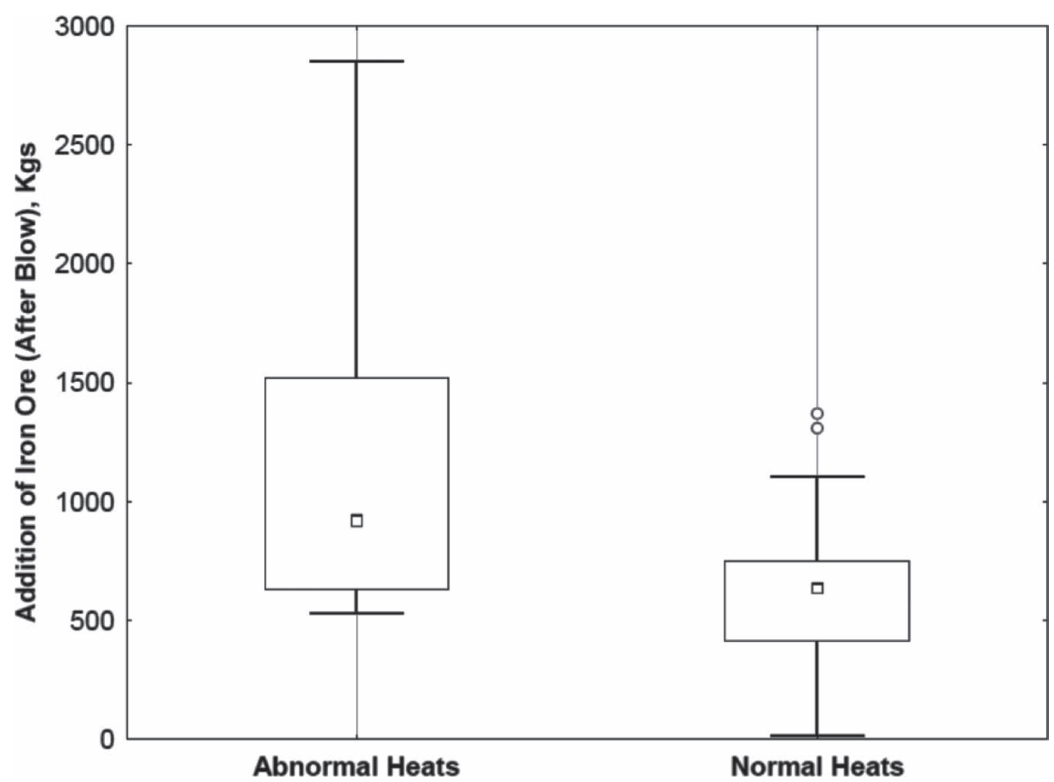

Fig. 11. Effect of addition of iron ore after blow is complete in $L D$ vessel.

given for a particular heat. So a purging index (PI) was calculated by dividing the amount of $\mathrm{HC}$ Fe-Mn addition made in LF with the time of purging given in LF. It can be observed from Fig. 10 that in one sequence, whenever purging index is greater than 30 , chances of abnormal behavior increased as in the cases of 4 th and 8th heat where abnormal sticky behavior was observed.

\subsubsection{Role of Iron Ore Addition as Coolant in Steel Mak- ing Vessel after Blowing}

A considerable amount of iron ore is added as a coolant in steelmaking after blow is complete in LD vessel. Addition of iron ore (which are generally wet during monsoon) increases the water vapor entrapment in primary steelmaking stage and hydrogen pick up takes place when the bath is killed during tapping. The effect of iron ore used as coolant can be seen from Fig. 11. It can be seen that ore addition of more than $700 \mathrm{~kg}$ for a 160 tonne LD converter creates problem of abnormal sticky behavior. So addition of iron ore as coolant is restricted to a certain level which helped in controlling hydrogen in steel.

Thermo-Gravitometry and Differential Scanning Calorimetry (TG-DSC) of iron ore was carried out in our lab to determine the presence of goethite $(\mathrm{FeO} . \mathrm{OH})$ in $\mathrm{LD}$ iron ore. It can be seen from Fig. 12 that, decomposition of goethite present in iron ore takes place at a temperature around

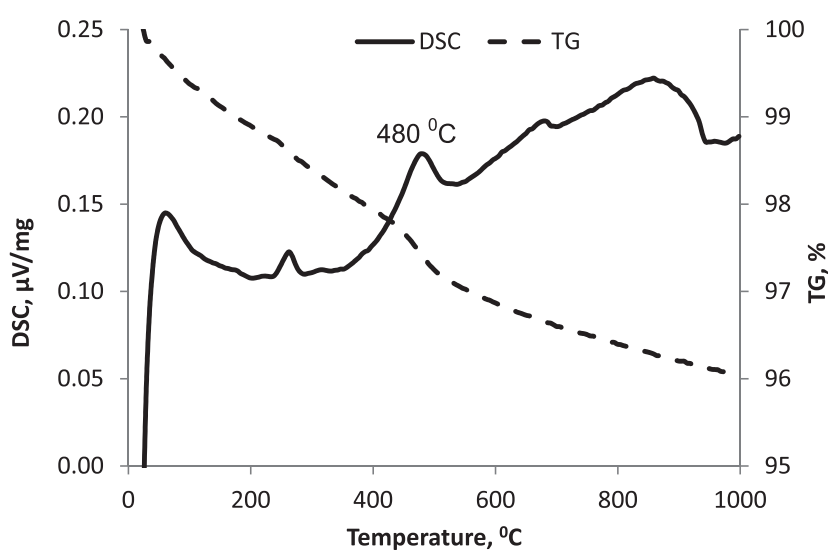

Fig. 12. TG-DSC analysis of iron ore samples added in vessel.

$480^{\circ}$ centigrade while experimenting under a controlled atmosphere. Following reaction which converts goethite to hematite takes place at a wide temperature range where moisture is released to the liquid steel.

$$
\text { 2FeO.OH }=\mathrm{Fe}_{2} \mathrm{O}_{3}+\mathrm{H}_{2} \mathrm{O}
$$

The moisture released from iron ore, increases the hydrogen content of steel when it is added as a coolant after vessel blowing operation. So restricting the iron ore addition as coolant to a level of $<4-4 \mathrm{Kg} /$ tonne of steel helps in lower 


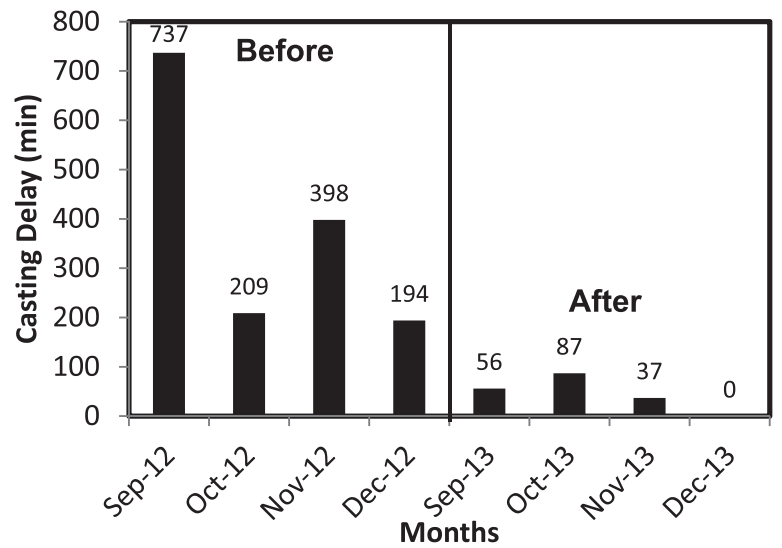

Fig. 13. Improvement in casting delay due to abnormal sticky behavior.

hydrogen content in liquid steel.

As moisture and hydroxides are the prime source of hydrogen in steel, addition of high moisture contacting raw material, or wet material and hydrated lime should be avoided during primary or secondary steelmaking practices. This should be followed by higher purging duration in both online purging (OLP) stations as well as in ladle furnace (LF).

\subsection{Improvement in Abnormal Sticky Behavior}

Abnormal sticky behavior during slab casting was reduced by a great extent after the findings were implemented in the plant. The results can be seen in Fig. 13, where month wise comparison of casting delay due to abnormal sticky behavior is presented before and after implementation of findings. It can be seen the problem could be tackled successfully.

\section{Conclusions}

Abnormal sticky behavior which results in sticker breakout is a common problem in many steel industries during humid season. In order to address this problem, the root cause of this problem has been analyzed through various plants and laboratory based experiments and a mechanism to control the above phenomena is presented. The following points can be inferred from the above study:
(1) There is not much compositional variation in mould slag between normal and abnormal heats suggesting compositional variation has negligible effect on abnormal sticky behavior (melting characteristic).

(2) Presence of large number of pores in the slag film contributes to poor heat transfer in abnormal heats

(3) Due to the presence of large number and bigger crystals, heat transfer through the slag film reduces drastically below the meniscus level and abnormal sticky behavior takes place in abnormal heats.

(4) Presence of $30-40 \%$ more hydrogen in liquid steel in the abnormal heats suggests that, hydrogen helped in crystallising the slag rapidly contributing to the abnormal sticky behavior.

(5) It was found that higher addition of $\mathrm{HC} \mathrm{Fe}-\mathrm{Mn}$ followed by lower purging duration in LF increases the chances of the problem as improper degassing takes place.

(6) Addition of iron ore as coolant after blow should be restricted to 4-5 Kg/ tonne of steel to reduce the hydrogen pick up in steel.

\section{REFERENCES}

1) K. Mills: ISS Steelmaking Proc., ISS, Warrendale, PA, (1991), 121.

2) M. Sus, K. Mills, M. Richardson, R. Taylor and D. Stewart: Ironmaking Steelmaking, 21 (1994), 279.

3) M. Kawamoto, K. Hakari and T. Watanabe: CAMP-ISIJ, 10 (1997), 890.

4) Y. Kashiwaya, C. E. Cicutti and A. W. Cramb: ISIJ Int., 38 (1998), 357.

5) X. Wang and D. Wu: Iron Steel, 32 (1997), 750.

6) M. Wolf: 74th Steelmaking Conf. Proc., ISS/AIME, Warrendale, PA, (1991), 51.

7) W. H. Emiling: Iron Steelmaker, 21 (1994), 47.

8) H. Mizukami, M. Hara, Y. Shirai and T. Watanabe: ISIJ Int., 44 (2004), 1714.

9) Y. Ueshima, T. Mizoguchi, Y. Takagi, K. Kondo and H. Kato: Tetsuto-Hagané, 98 (2012), 526

10) P. J. Zasowski and D. J. Sosinsky: 73rd Steelmaking Conf. Proc., ISS/ AIME, Warrendale, PA, (1990), 253

11) P. J. Zasowski, R. V. Branion, D. C. Mooney, W. Stolnacker and R. P. Stone: 72nd Steelmaking Conf. Proc., ISS/AIME, Warrendale, PA, (1989), 393.

12) J. N. Pontoire, C. Lefebvre, J. L. Friscourt and J. P. Lopez: Rev. Metall., (1996), 1237.

13) J. N. Pontoire, J. P. Radot, V. Delvaux and E. Dhaussy: Rev. Metall., 97 (2000), 35

14) T. Kajitani, Y. Kato, K. Harada, K. Saito, K. Harashima and W. Yamada: ISIJ Int., 48 (2008), 1215. 